\title{
Reference Area Investigation in a Gas Turbine Combustion Chamber Using CFD
}

\author{
Fagner Luis Goular Dias, ${ }^{1, *}$, Marco Antonio Rosa do Nascimento ${ }^{1}$, Lucilene de Oliveira Rodrigues ${ }^{1}$ \\ Universidade Federal de Itajubá- UNIFEI, Instituto de Engenharia Mecânica, Itajubá, Minas Gerais, Brasil
}

\begin{abstract}
The gas turbine combustion chamber is one of the most critical components to be designed, because it must ensure a stable operation in a wide range of air/fuel ratio and load. Among several calculations involved in the design of a combustion chamber, the reference area is the most important physical parameter, especially by the great impact on other dimensions. In general, this parameter must be calculated from an analysis of the limitations imposed both chemical reactions and aerodynamics, i.e., based on combustion process requirements and maximum pressure drop allowable in the combustion chamber, respectively. So, the aim of this paper is investigate the influence of the reference area in the velocity profile, in the temperature distribution, in the mixing process and in the flame behavior, according to the reference area used in the combustion chamber. These numerical analyses were carried out using ANSYS CFX®, comparing them with the base value calculated by Lefebvre [5], for a thermodynamic cycle of $600 \mathrm{~kW}$ gas turbine engine, conduced in GateCycle ${ }^{\circledR}$ program. Finally, it can be concluded that some changes in the reference area calculated by Lefebvre [4] produces better results, especially by improving the burning process and the behavior of the flame.
\end{abstract}

Keywords Combustion chamber, Gas turbine, Can-combustion, CFD simulations, ANSYS CFX ${ }^{\circledR}$

\section{Introduction}

The use of gas turbines engines for electrical power generation, in comparison with other technologies, has increased. In a paper published by Forecast International consultancy, the gas turbine market is expected to generate $\$ 118.4$ billion for the period 2005-2014. Facing the global policies to reduce pollutants emissions and the prospect of the exhaustion of fossil fuels, gas turbines engines operating in a wide range of fuels have been studied in several researches centers around the world [4]. In this context, the development of technologies related to combustion chambers of gas turbines has achieved importance, for higher combustion efficiency and reducing emissions [3].

Pavlas et al. [9] has shown the growth of renewable energy sources for power electrical generation, and proposed alternatives that not change completely the original design. In gas turbine applications, some modifications are required to meet the different characteristics, compositions and calorific value of fuels considered off-design [5, 7]. Bonzano and Pollarolo [1] reported the gas turbines demand for operating with of low heating value fuels. In researches, it described the major impacts of these fuels in the combustion system design.

* Corresponding author:

fagner@unifei.edu.br (Fagner Luis Goular Dias)

Published online at http://journal.sapub.org/jmea

Copyright (C 2014 Scientific \& Academic Publishing. All Rights Reserved
Neilson [8] has studied the requirements for a gas turbine LM2500, manufactured by GE Energy ${ }^{\circledR}$, for operating with low heating value fuels.

Cameretti et al. [2] investigated the employment of liquid and gaseous bio-fuels in a micro-gas turbine. For the liquid fuel supply, a new shape and location of the main fuel injector was combined with a modified position of the pilot injector in order to reduction of the thermal and prompt NO formation by approaching the flameless combustion concept.

As demonstrated, several studies have been performed highlighting the fuel replacement possibility, after just some modifications in the initial design, according to the characteristics of each fuel. In this case, it's important create tools that will provide the basic modifications required for the new operating condition, even during the preliminary design, based on the fuel composition, in order to facilitate and to enable the replacement process mentioned above. However, like the reference area is the most important parameter in the combustion chamber, this paper aims to investigate, through numerical simulations conducted by ANSYS CFX ${ }^{\circledR}$, the flame behavior according to initial reference area proposed by Lefebvre [6].

\section{Reference Area}

The reference area represents one of the most important physical design parameter of a gas turbine combustion chamber, creating great impact on other dimensions. 
According to Lefebvre [6], this parameter must be calculated (1) by taking a compromise between the limitations given by the chemical reactions and aerodynamic, and the maximum pressure loss allowable.

Thus, the calculations are made taking into account two possibilities (aerodynamics and chemical reactions), choosing the greater value of area:

$$
A_{r e f}=\frac{\pi D_{r e f}^{2}}{4}
$$

\subsection{Approach Based on Aerodynamics}

From this approach, the calculations concerning the main dimensions of the combustion chamber are based on pressures losses. The main quantities related (2) to the pressure losses may be associated [6]:

$$
\frac{\Delta P_{3 \rightarrow 4}}{P_{3}}=\frac{\Delta P_{3 \rightarrow 4}}{q_{r e f}} \frac{k}{2} M a_{r e f}^{2}
$$

Or, replacing $M a_{\text {ref }}$ and after some manipulations (2):

$$
\frac{\Delta P_{3 \rightarrow 4}}{P_{3}}=\frac{R_{a}}{2} \frac{\Delta P_{3 \rightarrow 4}}{q_{r e f}}\left(\frac{\dot{m} \sqrt{T_{3}}}{P_{3} A_{r e f}}\right)^{2}
$$

From (3) is possible to get the reference area value, $A_{\text {ref }}$ :

$$
A_{r e f}=\left[\frac{R_{a}}{2}\left(\frac{\dot{m}_{3} \sqrt{T_{3}}}{P_{3}}\right)^{2}\left(\frac{\Delta P_{3 \rightarrow 4} / q_{r e f}}{\Delta P_{3 \rightarrow 4} / P_{3}}\right)\right]^{0.5}
$$

The total pressure loss, $\Delta P_{3 \rightarrow 4}$, used in previous (4) corresponds to a design value, i.e., a value given by the numerical simulation of cycle (compressor/turbine) for a given pressure drop percent. Due to the fact that this project develops a tubular chamber, where pressure losses throughout the combustion chamber are around 6-8\%, it was defined as an initial approximation that, the pressure loss in flame tube to be around $5 \%$. Then, these $5 \%$ of pressure loss were equally divided in three regions, i.e., the nozzle injector until the end of the primary zone, the secondary zone and in the ending of the dilution zone. The preliminary design begins with some typical values, achieved by several experiments. Lefebvre [6] suggests some typical values, according to the type of combustion chamber (tubular, annular and annular-tube), listed in the Table 1:

In the Table 1, among these parameters, the pressure loss in the chamber, $\Delta P_{3 \rightarrow 4} / P_{3}$, is a design parameter and therefore, fixed. The value of pressure loss factor, $\Delta P_{3 \rightarrow 4} / q_{\text {ref }}$, is a function of the "pattern factor", the emission of pollutants, the compressor outlet velocity and the diffuser's type [6]. Finally, the parameter, $\dot{m}_{3} \sqrt{T_{3}} /\left(P_{3} A_{\text {ref }}\right)$, varies according to the reference area chosen. As before, the detailed calculation of these parameters is not feasible, and once they are bound by (4), were used data which corresponds to the tubular type shown in the table.

Table 1. Typical values used in combustion chambers

\begin{tabular}{cccc}
\hline $\begin{array}{c}\text { Type of } \\
\text { chamber }\end{array}$ & $\Delta P_{3 \rightarrow 4} / P_{3}$ & $\Delta P_{3 \rightarrow 4} / q_{\text {ref }}$ & $\dot{m}_{3} \sqrt{T_{3}} /\left(P_{3} A_{\text {ref }}\right)$ \\
\hline Tubular & 0.07 & 37 & 0.0036 \\
Annular-tube & 0.06 & 28 & 0.0039 \\
Annular & 0.06 & 20 & 0.0046 \\
\hline
\end{tabular}

\subsection{Approach Based on Combustion Process}

The determination of an appropriate reference area for chemical reactions can be obtained through the parameter, $\theta$. According to Lefebvre [6] to any fuel/air ratio, the combustion efficiency, $\eta$, can be related based on the parameter $\theta$, as follows (5):

$$
\theta=\frac{P_{3}^{1.75} A_{r e f} D_{r e f}{ }^{0.75} e^{T_{3} / b}}{\dot{m}_{3}}
$$

Considering the combustion efficiency about $100 \%$, the parameter $\theta$ has a value $73 \times 10^{-6}$ (SI) [6]. Finally, given the values to the reference area, $A_{\text {ref }}$, obtained by both approaches, the value considered will be the greatest.

\section{Methodology}

The methodology proposed by Lefebvre [6] aims to provide the main dimensions of a tubular combustion chamber gas turbine, according to input data. Initially are computed the reference parameters, based on the requirements of mass flow, temperature and reference area used. These quantities are used for analysis and comparison with other arrangements for combustion chambers and are typically associated with flow characteristics, such as velocity, Mach number and dynamic pressure. The different sections of the combustion chamber were defined based on mass distribution and combustion regime. Also, it was determined the dimensions of the diffuser, the swirler, the primary, secondary and dilution zones, according to the characteristics of the flow. All calculations required by the methodology were automated by an Excel ${ }^{\circledR}$ spreadsheet developed, as illustrated in Figure 1. It was created different plans, where the calculations have been grouped according to some affinity established. 


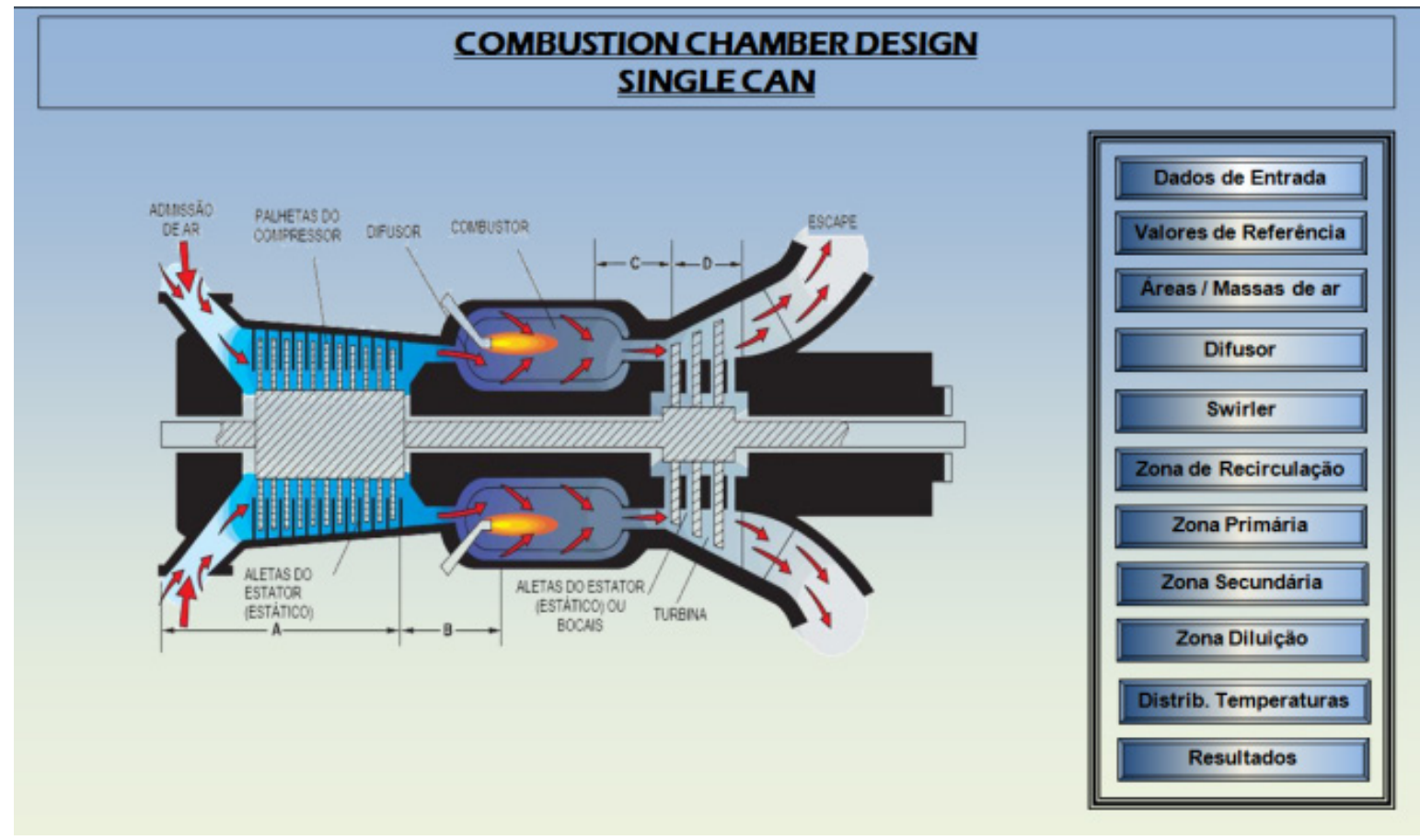

Figure 1. Initial screenshot of the Excel ${ }^{\circledR}$ spreadsheet developed

\section{Standard Design}

For this simulation, considered standard, the geometry of the combustion chamber was designed with input data listed in Table 2, achieved by GateCycle ${ }^{\circledR}$ in Rodrigues [10] for a gas turbine combustion chamber of $600 \mathrm{~kW}$.

The chemical composition of fuel used in this simulation is described in Table 3.

Table 2. Inputs to the simulations - case 1

\begin{tabular}{ccc}
\hline Parameters & Values & Units \\
\hline Air mass flow rate & 4.288 & $\mathrm{~kg} / \mathrm{s}$ \\
Inlet air temperature & 461.0 & $\mathrm{~K}$ \\
Inlet total pressure of air & 4.053 & $\mathrm{bar}$ \\
Inlet static pressure of air & 3.899 & $\mathrm{bar}$ \\
Mass flow rate of fuel & 0.745 & $\mathrm{~kg} / \mathrm{s}$ \\
Inlet fuel temperature & 430.0 & $\mathrm{~K}$ \\
Inlet total pressure of fuel & 4.053 & $\mathrm{bar}$ \\
Velocity of fuel injection & 15.0 & $\mathrm{~m} / \mathrm{s}$ \\
Outlet temperature & 1123.0 & $\mathrm{~K}$ \\
Pressure loss & 6.0 & $\%$ \\
Combustion efficiency & 0.99 & - \\
\hline
\end{tabular}

Table 3. Natural gas composition used in the simulations - case 1

\begin{tabular}{cc}
\hline Chemical formula, - & Mass fraction, - \\
\hline $\mathrm{CH}_{4}$ & 0.8856 \\
$\mathrm{C}_{2} \mathrm{H}_{6}$ & 0.0917 \\
$\mathrm{CO}_{2}$ & 0.0065 \\
$\mathrm{C}_{3} \mathrm{H}_{8}$ & 0.0042 \\
$\mathrm{~N}_{2}$ & 0.0120 \\
\hline
\end{tabular}

From the calculations carried out by Excel ${ }^{\circledR}$ spreadsheet developed, it was obtained the preliminary geometry of a tubular combustion chamber gas turbine, as illustrated in the Figure 2.

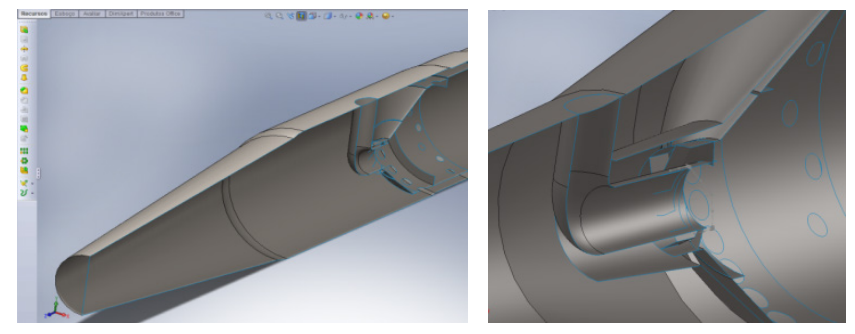

Figure 2. Geometry designed by the Excel ${ }^{\circledR}$ spreadsheet developed

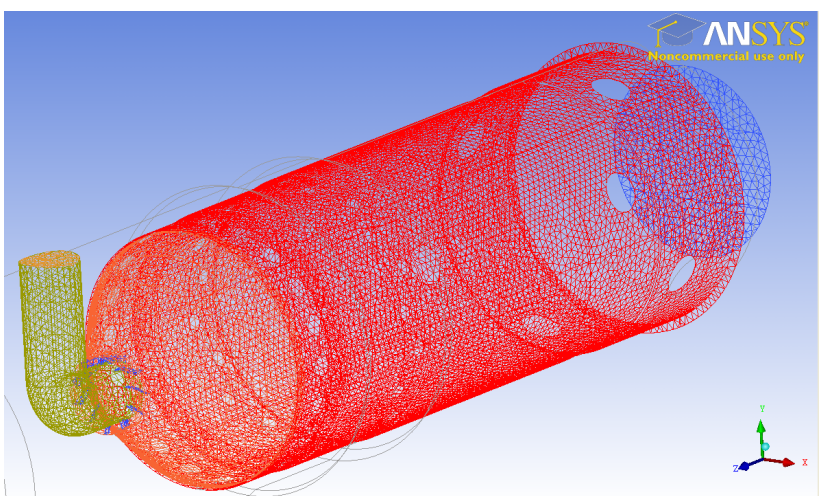

Figure 3. Mesh details for Simulation 1

The solid model obtained must be converted into a mesh, as shown in Figure 3. The mesh is chosen unstructured tetrahedral type, the most suitable for complex geometries. In the global network, we used elements of size $0.010 \mathrm{~m}$, with 15 adjustment iterations. However, because of the complexity of the geometry, further improvements were 
carried out in dilution holes and the swirler blades, with a maximum element size of $0.008 \mathrm{~m}$. In the end, the mesh created resulted in 2.7 million items placed in 4600 nodes.

Due to the composition of fuel used, natural gas, it was employed lists of reactions: Ethane Air WD, Methane Air WD1 NO PDF e Propane Air WD1. The turbulence model used was Shear Stress Transfer, SST, and for combustion process the Eddy Dissipation model. The turbulence model was chosen by good results reported [10] in similar applications. The Eddy Dissipation model was chosen because it is a general model and consider, among other factors, a turbulent burning and a diffuse flames. Finally, the P1 model was used to calculate radiation heat transfer, also recommended by Rodrigues [10]. Following the preparation of geometry and attributed the boundary conditions associated, the simulations results using ANSYS CFX ${ }^{\circledR}$ are described below.

\section{Results of Numerical Simulations}

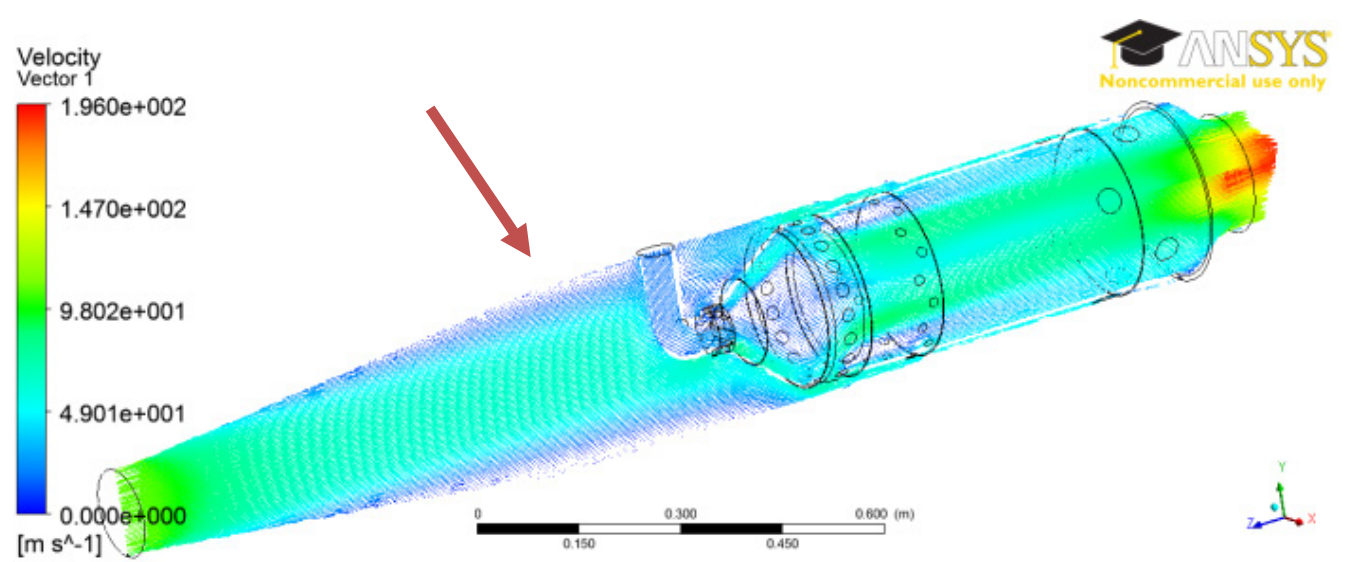

(a)

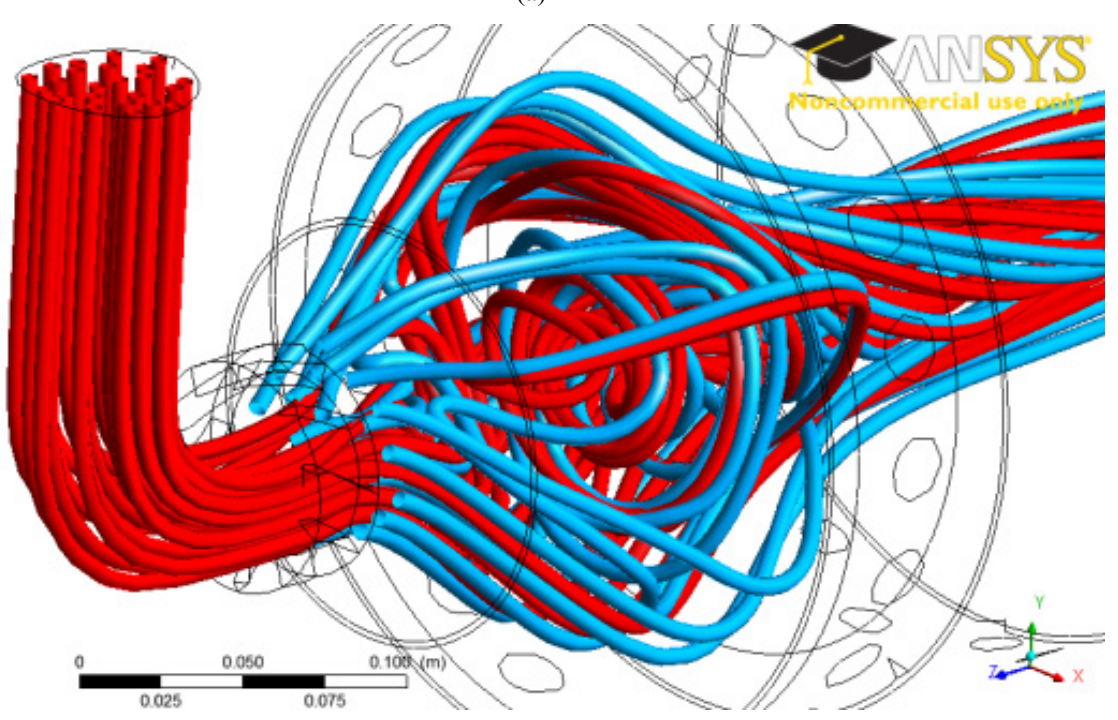

(b)

Figure 4. Flow distribution along the combustion chamber, simulation 1: a) velocity vectors, YZ longitudinal plan, b) streamlines, primary zone 
In Figure 5 the flame temperature presents high values from the extremities to the central region of the chamber, showing the difficulty of mixing the air flow with fuel in the primary region, previously observed. Thus, as the airflow dragged just a part of the fuel, the fact that temperatures were elevated in the extremities is compatible. Furthermore, this reflects in a difficulty of mixing and in long flame, with high temperatures near the wall and output the chamber.
Finally, it can be noted by the temperature distribution in the outlet plane, Figure 6, that there are some hot spots, even small, but could affect the integrity of turbine blades. The average temperature at exit of the combustion chamber was $1028.17 \mathrm{~K}$, close to the value estimated by Excel ${ }^{\circledR}$ spreadsheet calculations and in agreement with the value set in the design of the combustion chamber as $1123 \mathrm{~K}$.

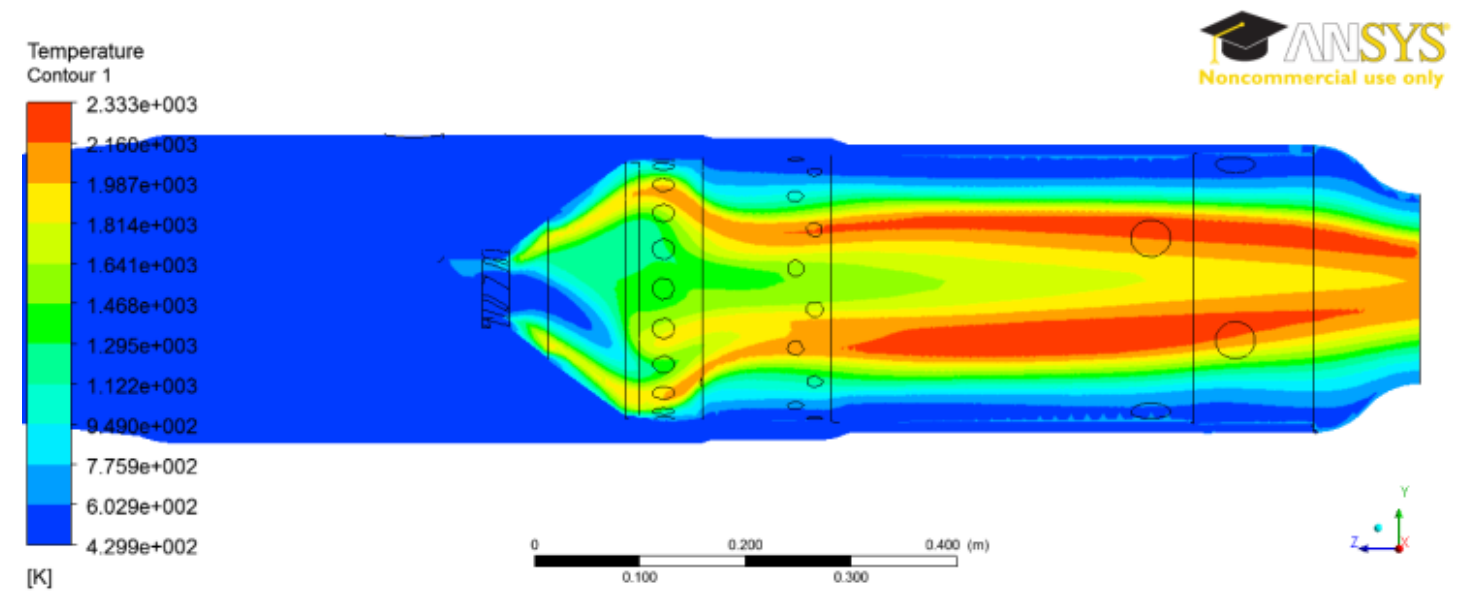

Figure 5. Temperature distribution in longitudinal plan $\mathrm{YZ}$

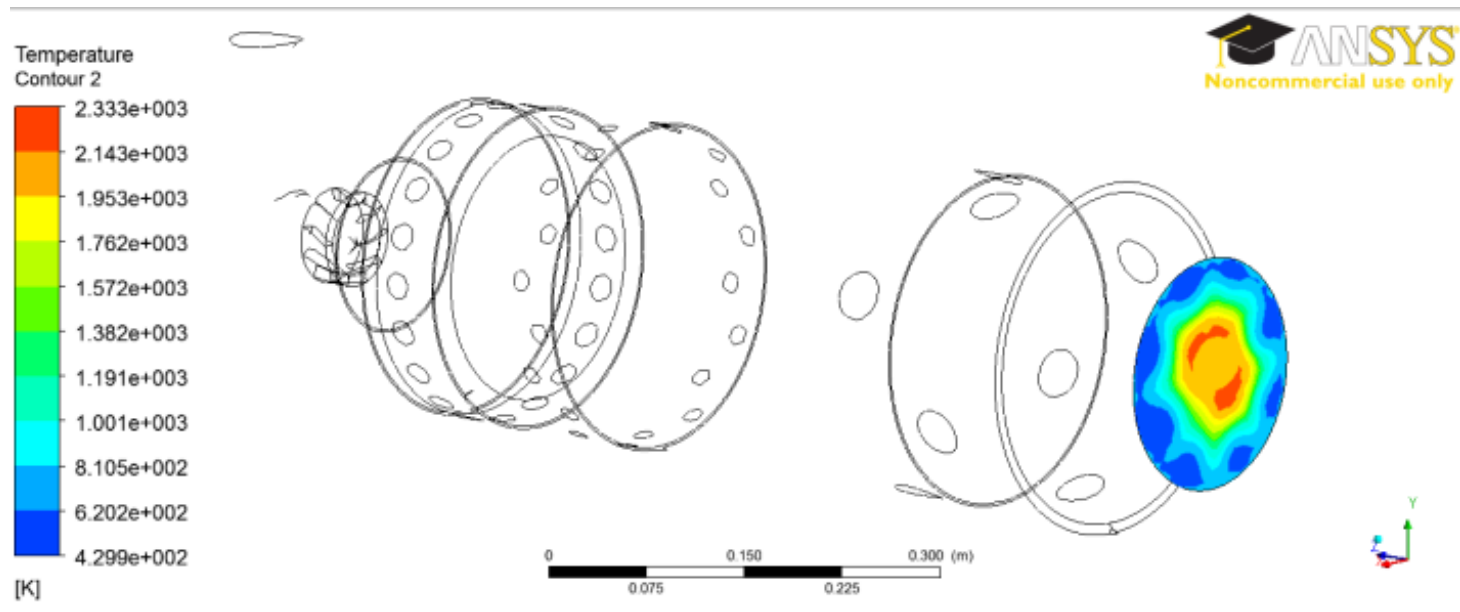

Figure 6. Temperature distribution at outlet plane

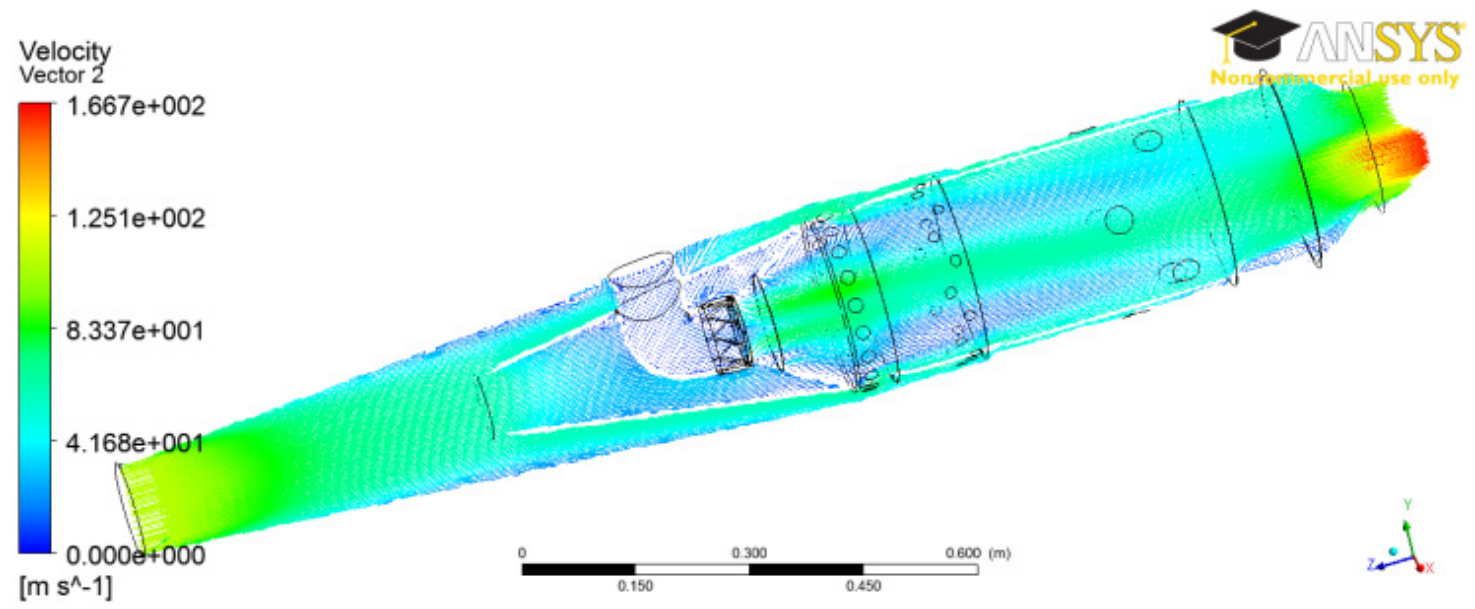

Figure 7. The flow distribution for the Simulation 2 


\subsection{Case 2}

It was carried out several improvements in the original geometry proposed by Lefebvre [6] methodology, in order to reduce the velocity inside the chamber and improve the burning process, especially by the placement of the snout, as shown in Figure 7. This should contribute to further reduce the arrival velocity in the swirl. In order to concentrate the flow in the central region, it was added a radial swirler, in order to prevent their adhesion to the walls of the dome, as shown in detail in Figure 9.

In a comparison between simulations 1 and 2, the Figure 8 shows the velocity reduction imposed by the snout, as expected.

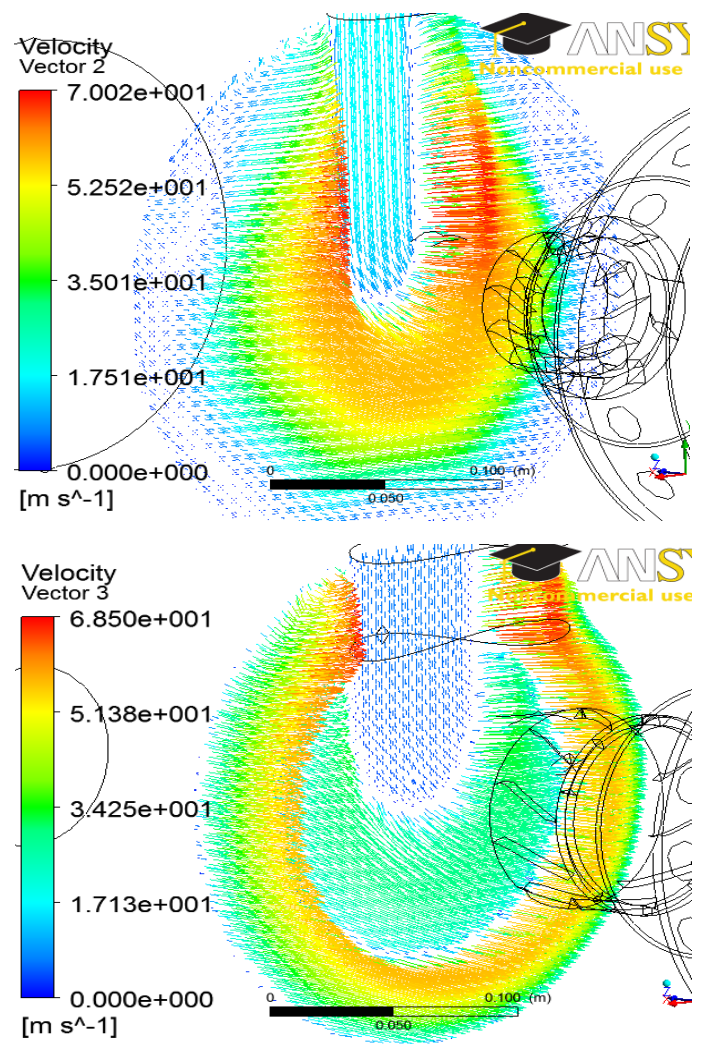

Figure 8. Intensity of local velocity vectors: a) without snout, b) with snout

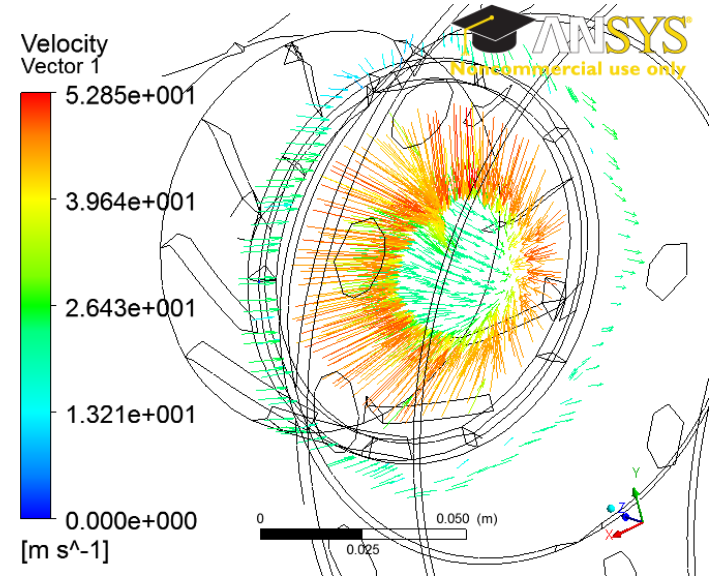

Figure 9. Details of outlet flow for the new swirler designed using axial and radial configurations

Faced with lower velocity in inside of the chamber, for example due to the introduction of the snout, the temperature profile remained more uniform, as can be verified in Figure 10.

This uniform temperature distribution reflects in the outlet plane, because lower velocities allow the reactions of the combustion process having time, as evidenced by Figure 11. As a consequence of a proper distribution of temperatures, the NO emission level will be lower, as shown in Figure 12.

According to the results obtained, the proposed improvements, in general, were positive. However, the temperature distribution in the chamber also presents a high temperature gradient, highlighting by the peripheral temperatures, as well as, a long length of flame, which may affect negatively the burning process. It was therefore proposed a change in the reference area initially calculated by Lefebvre [6] methodology, as described in case 3.

\subsection{Case 3}

During the simulations, it was noted that a reduction of arrival velocity at swirler has improved the distribution of the flame along the chamber, as well as, the velocity profile after the modifications. Also, the swirler outlet flow was improved, by concentrating it in the central region.

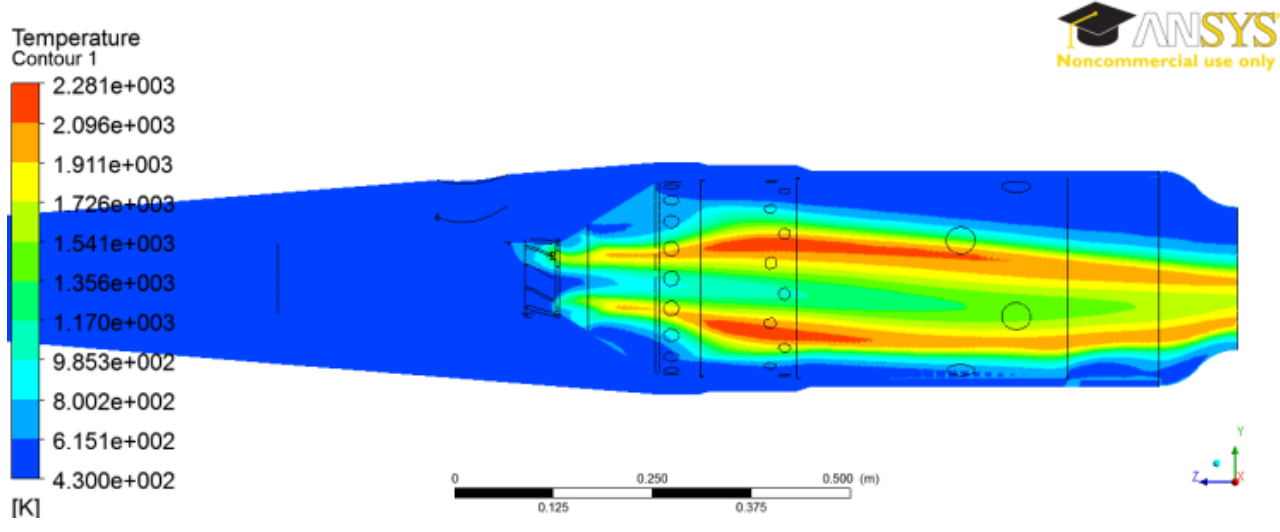

Figure 10. Temperature distribution for the Simulation 2 


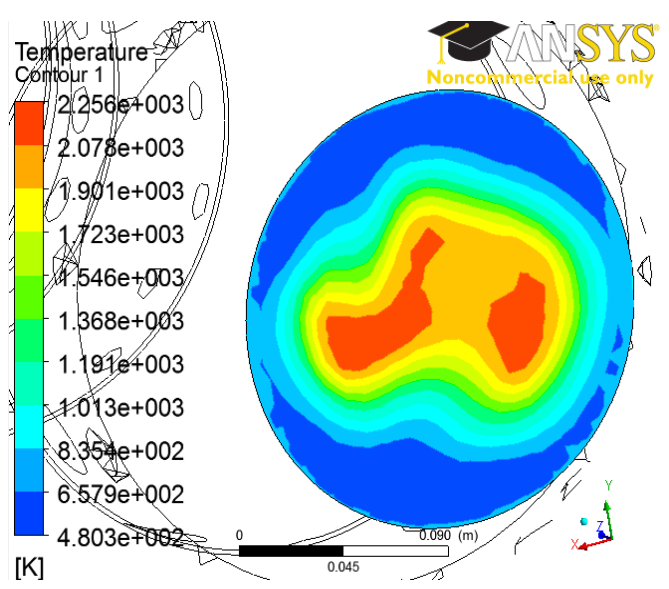

(a)

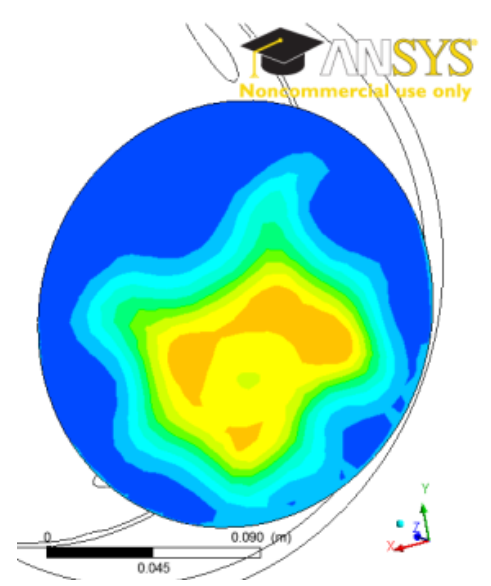

(b)

Figure 11. Comparison of outlet temperature distribution: (a) Simulation 1, (b) Simulation 2.

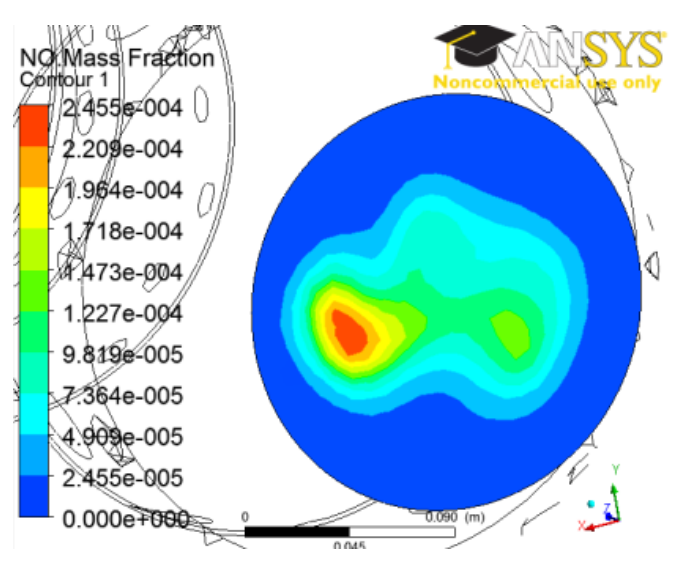

(a)

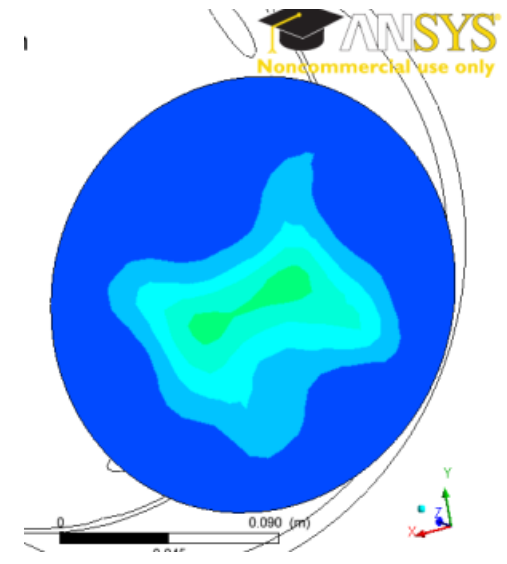

(b)

Figure 12. Comparison of outlet NO distribution: (a) Simulation 1, (b) Simulation 2

However, the high velocity of flow inside the chamber still persists, even after the changes proposed. In this sense, the reduction of flow velocity inside the chamber will only be possible from an increase in the reference area, initially calculated by Lefebvre [6], once the diffuser, the snout and the swirler already were investigated.

Table 4. Design data of Solar Turbines [7]

\begin{tabular}{ccc}
\hline Variable & Value & Unit \\
\hline Air mass flow rate & 0,95 & $\mathrm{~kg} / \mathrm{s}$ \\
Inlet total pressure & 4,053 & $\mathrm{bar}$ \\
Reference area & 0.038118224 & $\mathrm{~m}^{2}$ \\
Inlet temperature & 473 & $\mathrm{bar}$ \\
Output power & 60 & $\mathrm{~kW}$ \\
\hline
\end{tabular}

In order to determine the appropriate reference area, it was investigated the geometric data of a combustion chamber annular, Model T-62T-32 to $60 \mathrm{~kW}$, manufactured by Solar Turbines, described in Rodrigues [10], from which we have access to the data. Based on data shown in the Table 4, the reference area obtained was $0.015 \mathrm{~m} 2$, away from the value employed by Solar Turbines, and with a reference velocity of $21.322 \mathrm{~m} / \mathrm{s}$. In this sense, the reference diameter initially obtained was varied, until the resulting area was close to that reported in Table 4. At the end, the initial diameter had to be increased by $60 \%$, resulting in a reference velocity of 8.329 $\mathrm{m} / \mathrm{s}$.

It was thought necessary to simulate this new combustion chamber, using now the calculations with the reference diameter increased $50 \%$. Therefore, the combustion chamber geometry has changed, adding more space for combustion process and reducing flow velocity, especially in the central region as shown in Figure 13.

By the changes carried out, may also be noted that the reduction of flow velocity in the flame tube favoured the combustion process and the entrance of air through the holes, as showed by the temperature distribution in Figure 14 and the mass fraction of $\mathrm{CH}_{4}$ in Figure 15.

Another advantage of the reference diameter increased can be seen in Figure 16, by the improvement in the mixing process. It was carried out a properly average distribution and more uniform temperature in the outlet plane. In Simulation 2, there were some hot spots with $2000.0 \mathrm{~K}$ of temperature, with an average of 905.2K. In the Simulation 3, the distribution was more uniform, though even with some hot spots, but with an average temperature of $1110.9 \mathrm{~K}$, close to the design value at $1123 \mathrm{~K}$. 


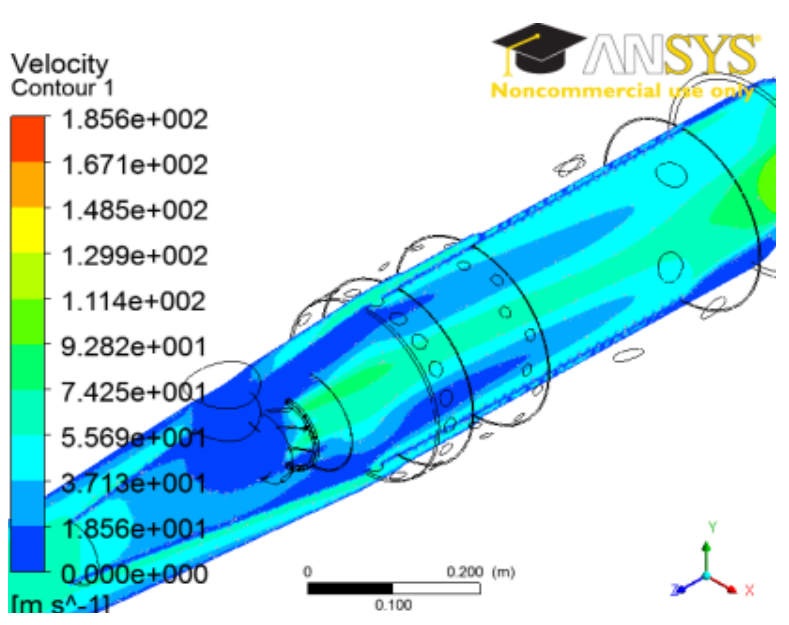

(a)

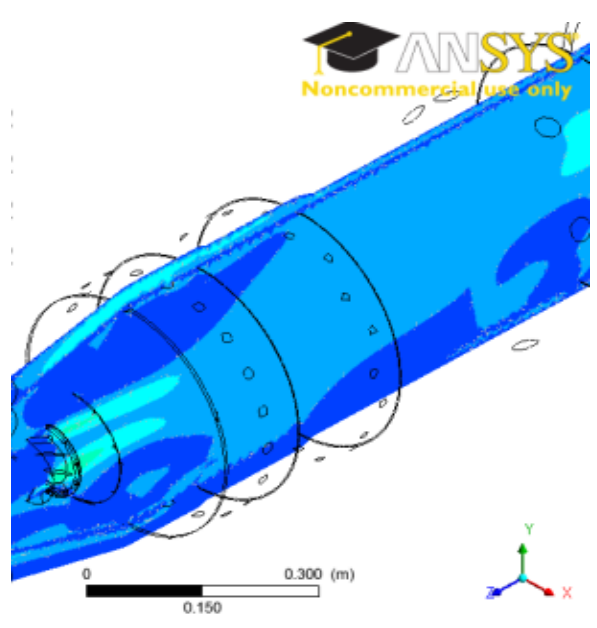

(b)

Figure 13. Comparison of velocity distribution in longitudinal plan YZ: (a) Simulation 2, (b) Simulation 3

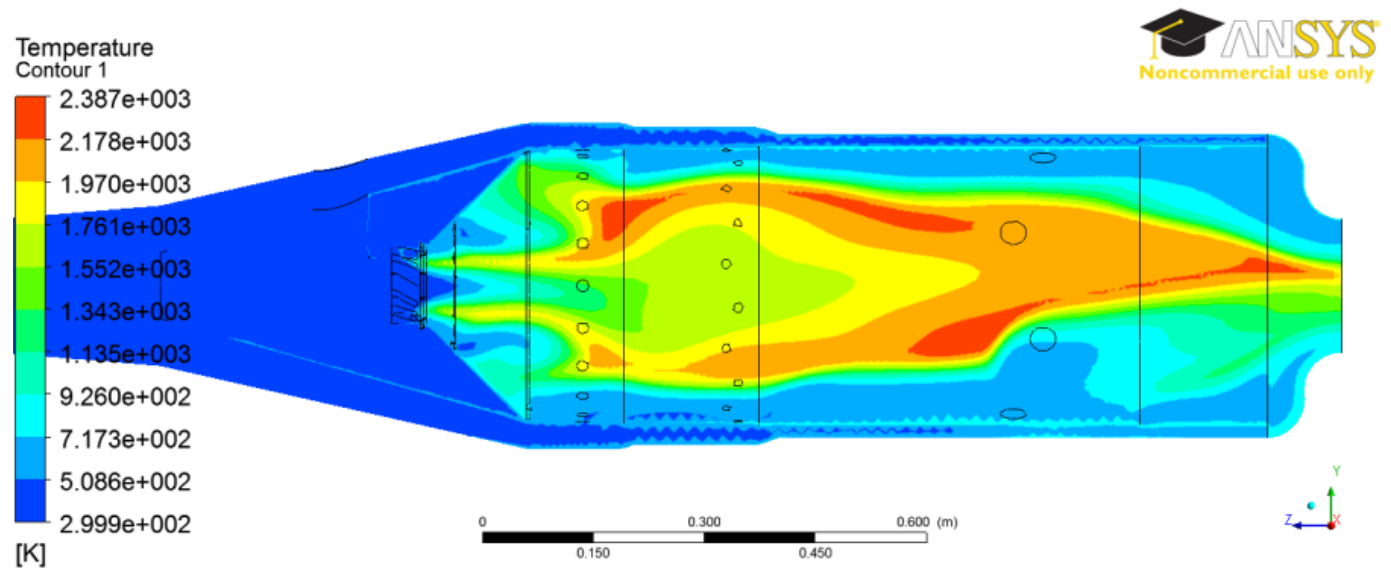

Figure 14. Temperature distribution in the longitudinal plan $\mathrm{YZ}$ for the Simulation 3

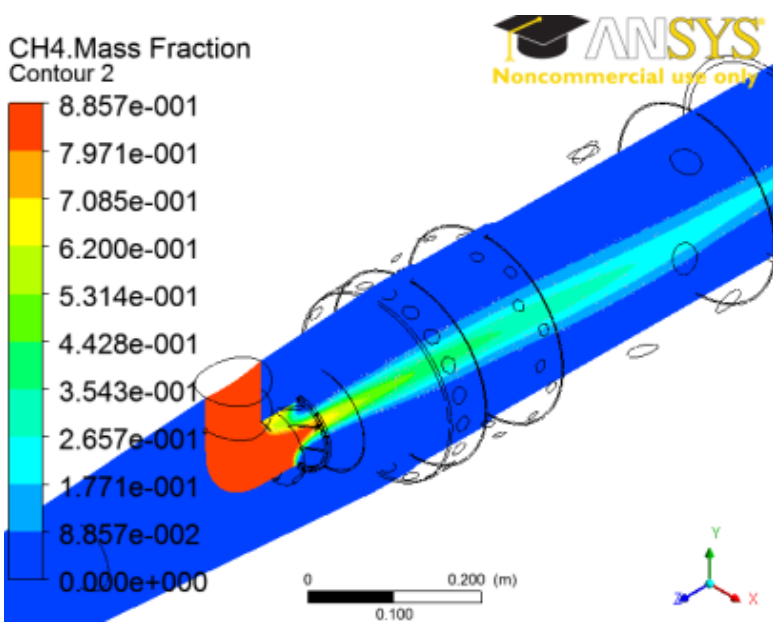

(a)

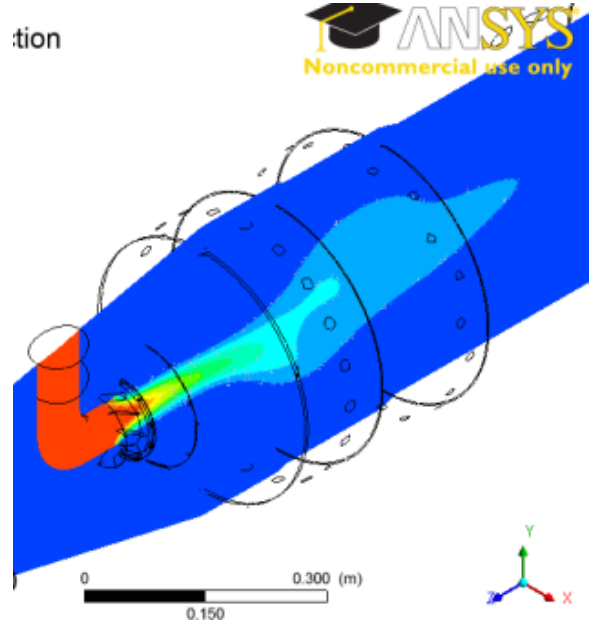

(b)

Figure 15. Comparison $\mathrm{CH}_{4}$ mass fraction: (a) simulation 2, (b) simulation 3 


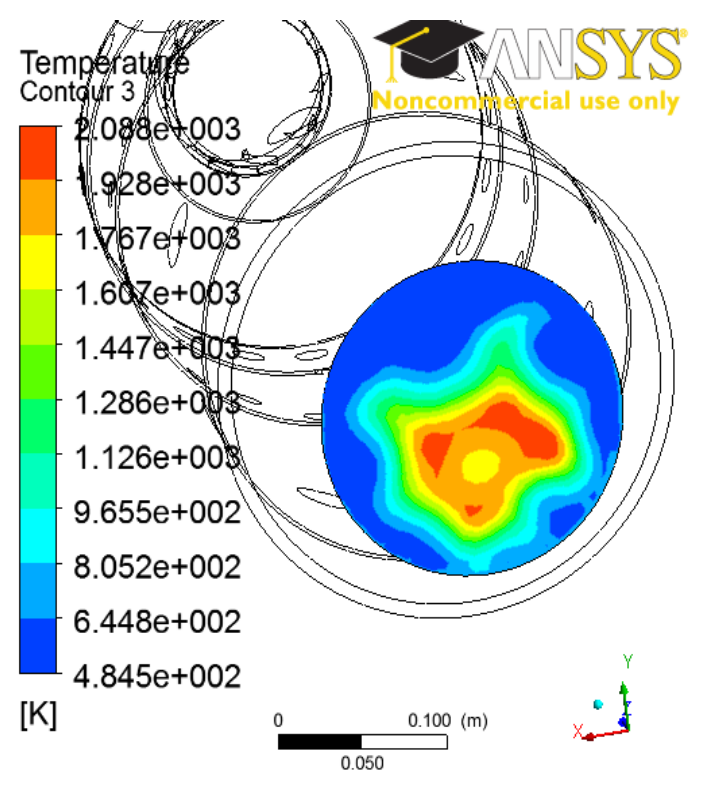

(a)

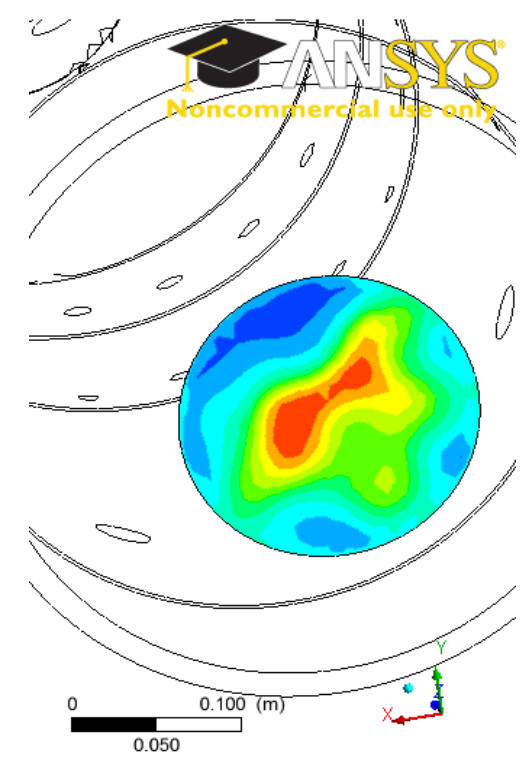

(b)

Figure 16. Comparison of temperature distribution in the outlet plane: (a) Simulation 2, (b) Simulation 3

\section{Conclusions}

According to the numerical simulations performed, the methodology developed by Lefebvre [6] presented good results. However, based on the geometric data provided by the methodology, the flow velocity within the combustion chamber remained high, even after some improvements imposed on the geometry. So, this scenario damaged the mixing process and favored an increase in pollutants emission, as a result of failures in the burning process. Thus, the increasing of reference area, as detailed in the Simulation 3 , was extremely important to reduce the burning rate in the region and improving the combustion process. These parameters used in the methodology proposed by Lefebvre [6] during the calculation of reference area must be evaluated, in order to adequate it to fuel characteristics, through their respective flame velocity.

\section{Nomenclature}

$\begin{array}{ll}\mathrm{A} & \text { reference area, } \mathrm{m}^{2} \\ \mathrm{~b} & \text { temperature correction factor, }- \\ \mathrm{D} & \text { reference diameter, } \mathrm{m} \\ \dot{m} & \text { mass flow rate, } \mathrm{kg} / \mathrm{s} \\ \mathrm{M}_{\mathrm{a}} & \text { Mach number, }- \\ \mathrm{P} & \text { total pressure, bar } \\ \mathrm{q} & \text { dynamic pressure, bar } \\ R & \text { gas constant, } \mathrm{kJ} / \mathrm{kmolK} \\ \mathrm{T} & \text { temperature, } \mathrm{K}\end{array}$

\section{Greek Symbols}

$\begin{array}{ll}\eta & \text { efficiency } \\ k & \text { ratio of specific heats } \\ \theta & \text { combustion efficiency }\end{array}$

\section{Subscripts and Superscripts}

$\begin{array}{ll}\text { ref } & \text { reference } \\ 3 \rightarrow 4 & \text { inlet to outlet of combustion chamber } \\ 3 & \text { combustion chamber inlet data } \\ \text { a } & \text { air }\end{array}$

\section{ACKNOWLEDGMENTS}

The authors gratefully acknowledge funding agencies CAPES, CNPq and FAPEMIG for their financials supports, which were essentials to the development of this work.

\section{REFERENCES}

[1] Bonzani F., Pollarolo G., Ansaldo Energia - Gas turbine operating experience with low BTU fuels, Turbo Expo 2004, Power for Land, Sea, and Air, Vienna, Austria, 2004.

[2] Cameretti, M.C., Tuccillo R., Piazzesi, R, Study of an exhaust gas recirculation equipped micro gas turbine supplied with bio-fuels, Applied Thermal Engineering, Volume 59, Issues 1-2, 162-173, 2013.

[3] Dias, F.L.G., Preliminary Design and Computational Simulation of Combustion Chamber of Gas Turbine Considering the Biofuels Combustion, Itajubá, 118p. Msc. Dissertation, Federal University of Itajubá, 2011.

[4] Gupta K.K., Rehman, A., Sarviya, R.M, Bio-fuels for the gas turbine: A review, Renewable and Sustainable Energy Reviews 14, 2946-2955, 2010.

[5] Hung, W.S.Y., Gas turbine fuels. Gas turbine technology seminar, San Diego, USA. 1989.

[6] Lefebvre A.H., Gas turbine combustion 2nd edition. USA: Taylor and Francis; 1998. 
[7] Mollière, M., Benefiting from the wide fuel capability of gas turbines: a review of application opportunities, ASME 2002 GT-2002-30017, 2002.

[8] Neilson C.E., LM2500 gas turbine modifications for biomass fuel operation. Biomass and Bioenergy 1998; 15(3):269-273, 1998.
[9] Pavlas M., Stehlik P., Oral J., Sikula J., Integrating renewable sources of energy into an existing combined heat and power system; 31:2499-2511, 2006.

[10] Rodrigues L.O., Parametric analysis of the combustion chamber of gas turbines using CFD [PhD thesis] Federal University of Itajubá, 2009. 